\title{
Formation of lysine 63-linked poly-ubiquitin chains protects human lung cells against benzo[a]pyrene- diol-epoxide-induced mutagenicity
}

Citation for published version (APA):

Langie, S. A., Knaapen, A. M., Ramaekers, C. H. M. A., Theys, J., Brun, J., Godschalk, R. W., van Schooten, F. J., Lambin, P., Gray, D. A., Wouters, B. G., \& Chiu, R. K. (2007). Formation of lysine 63linked poly-ubiquitin chains protects human lung cells against benzo[a]pyrene-diol-epoxide-induced mutagenicity. Dna Repair, 6(6), 852-862. https://doi.org/10.1016/j.dnarep.2007.02.012

Document status and date:

Published: 01/06/2007

DOI:

10.1016/j.dnarep.2007.02.012

Document Version:

Publisher's PDF, also known as Version of record

\section{Document license:}

Taverne

Please check the document version of this publication:

- A submitted manuscript is the version of the article upon submission and before peer-review. There can be important differences between the submitted version and the official published version of record.

People interested in the research are advised to contact the author for the final version of the publication, or visit the DOI to the publisher's website.

- The final author version and the galley proof are versions of the publication after peer review.

- The final published version features the final layout of the paper including the volume, issue and page numbers.

Link to publication

\footnotetext{
General rights rights.

- You may freely distribute the URL identifying the publication in the public portal. please follow below link for the End User Agreement:

www.umlib.nl/taverne-license

Take down policy

If you believe that this document breaches copyright please contact us at:

repository@maastrichtuniversity.nl

providing details and we will investigate your claim.
}

Copyright and moral rights for the publications made accessible in the public portal are retained by the authors and/or other copyright owners and it is a condition of accessing publications that users recognise and abide by the legal requirements associated with these

- Users may download and print one copy of any publication from the public portal for the purpose of private study or research.

- You may not further distribute the material or use it for any profit-making activity or commercial gain

If the publication is distributed under the terms of Article 25fa of the Dutch Copyright Act, indicated by the "Taverne" license above, 


\title{
Formation of lysine 63-linked poly-ubiquitin chains protects human lung cells against benzo[a]pyrene-diol-epoxide-induced mutagenicity
}

\author{
Sabine A.S. Langie ${ }^{a, 1}$, Ad M. Knaapen ${ }^{a, 1}$, Chantal H.M.A. Ramaekers ${ }^{b, 1}$, Jan Theys ${ }^{b}$, \\ Jan Brun ${ }^{c}$, Roger W.L. Godschalk ${ }^{a}$, Frederik J. van Schooten ${ }^{a}$, Philippe Lambin ${ }^{b}$, \\ Douglas A. Gray ${ }^{c}$, Bradly G. Wouters ${ }^{b}$, Roland K. Chiu ${ }^{b, *}$ \\ a Department of Health Risk Analysis and Toxicology (NUTRIM), Maastricht University, The Netherlands \\ b Department of Radiation Oncology (GROW), Maastricht University, The Netherlands \\ c Ottawa Health Research Institute, Ottawa, Ont., Canada
}

\section{A R T I C L E I N F O}

\section{Article history:}

Received 10 May 2006

Received in revised form

30 January 2007

Accepted 1 February 2007

Published on line 28 March 2007

\section{Keywords:}

Benzo(a)pyrene

DNA damage tolerance

Mutagenesis

Translesion synthesis

Ubiquitin

\begin{abstract}
A B S T R A C T
Benzo[a]pyrene exerts its mutagenic effects via induction of benzo[a]pyrene-diol-epoxide (BPDE)-DNA adducts. Such helix-distorting adducts are not always successfully repaired prior to DNA replication, which may result in a blocked replication fork. To alleviate this stall, cells utilize DNA damage tolerance systems involving either error-free damage avoidance or error-prone translesion synthesis. Studies in yeast suggest the modification of PCNA by lysine 63-linked poly-ubiquitin (K63-polyUb) chains as a key mediator of the error-free damage avoidance pathway. Recently, we extended this observation to human cells, showing the occurrence of poly-ubiquitination of PCNA in UV-irradiated human cells. In the present study, we hypothesized that disrupting the formation of K63-polyUb chains inhibits damage avoidance and favors error-prone repair involving low-fidelity polymerases (e.g. POL $)$ ), causing increased BPDE-induced mutagenicity. To test this hypothesis, we generated A549 cells expressing either a mutant ubiquitin $(\mathrm{K} 63 \mathrm{R}-\mathrm{Ub})$ which blocks further ubiquitination through $\mathrm{K} 63$, or the wild type ubiquitin (WT-Ub). We show that PCNA is poly-ubiquitinated in these cells upon BPDE-exposure and that disruption of K63-polyUb chain formation has no effect on BPDE-induced toxicity. In contrast, significantly higher frequencies of BPDE-induced HPRT mutations were observed in K63R-Ub expressing cells, of which the majority (74\%) was G $\rightarrow \mathrm{T}$ transversion. BPDE treatment caused an enhanced recruitment of POL $\eta$ to the replication machinery of the K63R-Ub expressing cells, where it co-localized with PCNA. Suppression of POL $\eta$ expression by using siRNA resulted in a 50\% reduction of BPDE-induced mutations in the K63R cells. In conclusion, we demonstrated that formation of K63-polyUb chains protects BPDE-exposed human cells against translesion synthesis-mediated mutagenesis. These findings indicate that K63-polyubiquitination guards against chemical carcinogenesis by preventing mutagenesis and thus contributing to genomic stability.
\end{abstract}

(c) 2007 Elsevier B.V. All rights reserved.

\footnotetext{
* Corresponding author at: Department of Radiation Oncology, Research Institute Growth and Development, Maastricht University, UNS 50/23, Room 5.240, PO Box 616, 6200 MD Maastricht, The Netherlands. Tel.: +31 43388 2908; fax: +31 433884540.

E-mail address: roland.chiu@maastro.unimaas.nl (R.K. Chiu).

1 These authors contributed equally to this work. 1568-7864/\$ - see front matter (C) 2007 Elsevier B.V. All rights reserved. doi:10.1016/j.dnarep.2007.02.012
} 


\section{Introduction}

Humans are continuously exposed to a wide variety of DNA-damaging environmental carcinogens such as polycyclic aromatic hydrocarbons (PAHs). The most studied PAH is benzo[a]pyrene $(\mathrm{B}[\mathrm{a}] \mathrm{P})$ whose mutagenic and carcinogenic potential has been demonstrated in both humans and animals [1]. After uptake, the chemically unreactive $\mathrm{B}[\mathrm{a}] \mathrm{P}$ is metabolically activated into its predominant reactive form, $( \pm$ )-anti-benzo[a]pyrene-7,8-dihydrodiol-9,10-epoxide (BPDE). This metabolite can covalently bind to the DNA, preferably to guanine, resulting in the formation of (+)-trans-anti-BPDE$\mathrm{N}^{2}-\mathrm{dG}$ being the most predominant adduct (>90\%) [1-3]. The formation of these $( \pm)$-anti-BPDE- $N^{2}-d G-D N A$ adducts is one of the key factors of $\mathrm{B}[\mathrm{a}] \mathrm{P}$-induced mutagenesis, producing mostly $\mathrm{G} \rightarrow \mathrm{T}$ transversions upon error-prone replication of adducted DNA templates [4].

Generally, nucleotide excision repair (NER) is the primary pathway to remove large helix-distorting DNA lesions, such as BPDE-DNA adducts. Nevertheless, despite NER activity and the presence of cell-cycle checkpoints, many of such bulky lesions may persist until replication, thereby stalling the replication fork. To avoid an aberrant cessation of the cell-cycle caused by such a blockage, cells have evolved DNA damage tolerance (DDT) systems (also known as post-replication repair) to circumvent the damage and continue replication in the presence of lesions [5,6]. Studies in bacteria (E. coli), yeast as well as mammalian cells [5-8], revealed that DDT can be accomplished through the action of error-prone low-fidelity translesion synthesis (TLS) polymerases (e.g. Y-family DNA polymerases). Studies in mammalian cells have revealed TLS to be an important mechanism in the response to BPDE-DNA adducts $[8,9]$. In general, TLS can either be error-free or errorprone, depending on the type of DNA damage, as well as the specific polymerase that is involved. Candidates for performing TLS bypassing bulky-DNA adducts are POL $\eta$, POLк, POLı, REV1 (Y-family polymerases) and POL $\zeta$ (B-family) $[6,10]$. In contrast to its anti-mutagenic role in response to UV radiation, bypass of $( \pm)$-anti-BPDE-DNA adducts by POL $\eta$ will promote mutagenesis by predominantly inserting the incorrect nucleotide opposite the lesion $[9,11]$.

There is now evidence showing that yeast have a second DDT pathway distinct from TLS, referred to as error-free damage avoidance. Although its mechanism is yet unclear, it may involve replication fork reversal, thereby using the information of the undamaged sister duplex at the replication fork $[12,13]$. Studies in yeast have shown that this pathway requires modification of proliferating cell nuclear antigen (PCNA) with lysine 63-linked polyUb (K63-polyUb) chains [12-14]. Specifically, upon exposure to DNA-damaging agents PCNA becomes mono-ubiquitinated by the ubiquitin conjugase-ubiquitin ligase (E2-E3) complex RAD6-RAD18 at its Lys164 residue, promoting its interaction with TLS-polymerases [12,15]. Subsequent Lys63-linked poly-ubiquitination of PCNA by the E2-E3 complex UBC13/MMS2-RAD5 then facilitates the error-free damage avoidance pathway. As far as we know, only studies in yeast and metazoans (i.e. X. laevis) confirmed this K63linked poly-ubiquitination $[12,14,16]$, and there is still debate on the importance of such damage avoidance mechanism in mammalian cells [17]. However, we recently demonstrated the formation of PCNA-linked polyUb polymers in UV-exposed human pulmonary epithelial cells (A549 cells) [18]. In addition, in the same study it was shown that formation of K63polyUb chains protected against UV-induced mutations. The aim of the present study was to investigate the effect of lysine 63-linked poly-ubiquitination processes on BPDE-induced mutagenesis in mammalian cells. To this end, we applied previously established A549 cell lines stably expressing ubiquitin either in its WT-form (WT-Ub) or as Lys63-mutants (K63R-Ub) which blocks further ubiquitination through K63 [18]. We show that PCNA is poly-ubiquitinated after BPDE treatment and that disruption of K63-polyUb chain formation enhances BPDEinduced mutagenicity, likely involving increased recruitment of the Y-family polymerase POL $\eta$. Therefore, we implicate the formation of these specific polyUb chains in the protection against chemical carcinogenesis.

\section{Materials and methods}

\subsection{Cell strains and culture}

As previously described, A549 cells were stably transfected with $6 \times$ his-tagged wild-type ubiquitin-GFP (WT-Ub-GFP) or K63R mutant ubiquitin-GFP (K63R-Ub-GFP) constructs using FuGene 6 (Roche Molecular Biochemicals, Mannheim, Germany) [19]. Plasmids were co-transfected with a plasmid conferring resistance to puromycin.

To study POLn-GFP foci formation, a set of A549 and HeLa cells were transfected with WT-Ub-puro or K63R-Ub-puro constructs using lipofectamine (Invitrogen Life Technologies, Carlsbad, CA). These Ub-puro cell lines were phenotypically comparable to the original Ub-GFP expressing cells as demonstrated by Chiu et al. [18].

To assess the role of POL $\eta$ in the mutagenicity of BPDE, K63R-Ub expressing A549 cells were transfected twice with SiGENOME SMARTpool reagent specific for human POLH (Dharmacon) using oligofectamine (Invitrogen). The transfections were done 72 and $24 \mathrm{~h}$ before treatment to achieve optimal long term knockdown of POLn of approximately 13-fold as determined by quantitative RT-PCR, as described previously [18].

Cells were cultured in a humidified atmosphere at $37^{\circ} \mathrm{C}(5 \%$ $\mathrm{CO}_{2}$ ), in DMEM (Sigma, St. Louis) supplemented with $10 \%$ heat inactivated FCS (Gibco Invitrogen, Scotland, UK) and 0.11\% filtered puromycin $(1 \mu \mathrm{g} / \mathrm{mL})$ to establish stable transfectants. For experiments, cells were cultured in DMEM supplemented with $10 \%$ heat inactivated FCS and $0.01 \%$ gentamicin, and grown until confluency.

\subsection{Cell treatments}

Before BPDE-exposure, medium was aspirated and cells were washed with sterile HBSS (-Ca/-Mg) (Gibco Invitrogen, Scotland, UK). BPDE (NCI Chemical Carcinogen Reference Standard Repository, Midwest Research Institute, Kansas City, MO) was dissolved in anhydrous dimethyl sulfoxide (DMSO, Merck, Darmstadt, Germany) at a concentration of $20 \mathrm{mM}$. This stock solution was diluted in culture medium to the desired concentrations of $0.1-1 \mu \mathrm{M}$ and immediately added to the cells. The 
final DMSO concentration was always 0.5\% [20]. After $30 \mathrm{~min}$ of incubation at $37^{\circ} \mathrm{C}$, medium containing BPDE was replaced by fresh culture medium. To study PCNA poly-ubiquitination, UV-irradiated cells were used as a positive control. This was performed on $80 \%$ confluent cells in 6 -cm dishes using a UVC (254-nm) germicidal lamp at a dose rate of $1 \mathrm{~J} / \mathrm{m}^{2} / \mathrm{s}$.

\subsection{Clonogenic cell survival}

The sensitivity of A549 cells expressing K63R-Ub or WT-Ub to BPDE was assayed using a clonogenic survival assay. Therefore, cells were seeded at a density of $4 \times 10^{5}$ cells $/ 60 \mathrm{~mm}$ dish (Falcon, Le Pont De Claix, France) and grown for $24 \mathrm{~h}$ before exposure to BPDE $(0-1.0 \mu \mathrm{M})$ or DMSO. Cells were treated for $30 \mathrm{~min}$ with the indicated dosages after which they were harvested and seeded at least in duplicate for each concentration. After $\sim 12$ days of growth the medium was removed and colonies were fixed and stained with $2 \%$ bromophenol blue in $70 \%$ ethanol. Any groupings of cells containing 50 or more cells were counted as a colony. For each dose, survival was calculated from the relative colony forming ability of the BPDE-exposed cells compared to the DMSO-treated controls. All experiments were normalized for the plating efficiency. $L_{50}$ values were estimated from the obtained concentration-response curves.

\subsection{HPRT-mutation analysis}

For the determination of HPRT-mutant frequencies in K63R$\mathrm{Ub}$ and WT-Ub expressing cells, cells were seeded at $1 \times 10^{6}$ cells/100 mm dish (Falcon, Le Pont De Claix, France) and cultured in hypoxanthine, aminopterin, and thymidine (HAT) supplemented culture medium for 1 week, to eliminate background HPRT mutations. Subsequently, cells were exposed to the indicated concentrations of BPDE $\left(30 \mathrm{~min}, 37^{\circ} \mathrm{C}\right)$ and were maintained for 1 week to allow for phenotypic expression of the acquired mutations. Cells carrying mutated HPRT were then selected in gentamicin-containing medium supplemented with $30 \mu \mathrm{M}$ 6-thioguanine (6-TG). After $\sim 14$ days of culture, cells were fixed and stained with $2 \%$ bromophenol blue in $70 \%$ ethanol. 6-TG resistant colonies consisting of 50 or more cells were counted. In parallel, cells were plated ( 200 cells $/ 100 \mathrm{~mm}$ dish) in medium lacking 6-TG to determine the plating efficiency at the time of selection. Mutation frequency for each treatment was calculated as follows; mutation frequency $=$ \# colonies $/$ (plating efficiency $\times$ \# cells seeded).

\subsection{Mutation spectrum}

BPDE-induced HPRT mutants were obtained as described above. To exclude sister clones only a single colony per treated population was isolated and grown in six-well plates until enough cells were obtained for RNA-isolation. Each sample was lysed in $1 \mathrm{~mL}$ Trizol and stored at $-20^{\circ} \mathrm{C}$ until use for RNA isolation. Total RNA was isolated from Trizol according to the manufacturer's protocol. Isolated RNA was purified using the RNeasy ${ }^{\circledR}$ Mini Kit (Qiagen) together with DNAse treatment (RNAse-free DNAse provided by Qiagen) according to the manufacturer's recommendations. Quantity and purity of the RNA was determined spectrophotometrically. cDNA was prepared using the iScript ${ }^{\mathrm{TM}}$ cDNA Synthesis kit (BioRad, CA, USA). The HPRT CDNA was amplified by PCR, followed by DNA sequencing on a ABI 3700 using a BigDye Terminator v1.1 cycle sequencing kit (Applied Biosciences) using the following overlapping primers: HPRT1 5'-CTT CCT CCT CCT GAG CAG TC-3'; HPRT2 5' -AAG CAG ATG GCC ACA GAA CT-3'; HPRT3 5'-CCT GGC GTC GTG ATT AGT G-3'; and HPRT4 5'-TTT ACT GGC GAT GTC AAT AGG A-3' [18].

\subsection{DNA isolation and ${ }^{32}$ P-postlabeling of BPDE-DNA adducts}

To study possible differences in BPDE-DNA adduct removal, A549 cells stably expressing K63R-Ub or WT-Ub were exposed to $0.1 \mu \mathrm{M}$ BPDE. After $30 \mathrm{~min}$ of incubation at $37^{\circ} \mathrm{C}$, medium containing BPDE was replaced by fresh culture medium and cells were harvested after $0,1,8$, and $24 \mathrm{~h}$ of recovery. Cells were centrifuged at $1000 \times g$ and pellets were stored at $-20^{\circ} \mathrm{C}$ until DNA isolation. Standard phenol extraction was used to obtain genomic DNA [21]. ${ }^{32} \mathrm{P}$-postlabeling was carried out using the nuclease PI enrichment technique as described by Reddy and Randerath with some modifications [21]. Briefly, an aliquot containing $10 \mu \mathrm{g}$ DNA was digested using micrococcal endonuclease $(0.25 \mathrm{U} / \mu \mathrm{L})$ and spleen phosphodiesterase $(2 \mu \mathrm{g} / \mu \mathrm{L})$ for $3.5 \mathrm{~h}$ at $37^{\circ} \mathrm{C}$. Subsequently, DNA-digests were treated with nuclease $\mathrm{P} 1(2.5 \mu \mathrm{g} / \mu \mathrm{L})$ for $30 \mathrm{~min}$ at $37^{\circ} \mathrm{C}$. To stop the NP1-reaction, $1 \mathrm{M}$ Tris ( $\mathrm{pH}$ 9.6) was added. BPDE-modified nucleotides were subsequently labeled with $\left(\gamma^{-32} \mathrm{P}\right)$ ATP $(50 \mu \mathrm{Ci}$ per sample; ICN, Indianapolis) using T4-polynucleotide kinase $(10 \mathrm{U} / \mu \mathrm{L})$ for $30 \mathrm{~min}$ at $37^{\circ} \mathrm{C}$. The radiolabeled adducted nucleotide biphosphates were separated on PEI-cellulose sheets (Machery Nagel, Düren, Germany) by multi-directional thin layer chromatography (TLC). In all experiments two BPDE-DNA standards with known adduct levels (1 adduct $/ 10^{7}$ nucleotides and 1 adduct $/ 10^{8}$ nucleotides) were analyzed in parallel for quantification purposes. Quantification was performed using Phosphor-Imaging technology (Fujifilm FLA3000).

Additionally, to assess the amount of DNA in the reaction, an aliquot of DNA-digest was diluted and labeled with $(\gamma$ $\left.{ }^{32} \mathrm{P}\right)$ ATP. Nucleotides were separated on a PEI-cellulose sheet by one directional TLC in $0.12 \mathrm{M} \mathrm{NaH}_{2} \mathrm{PO}_{4}(\mathrm{pH} 6$ ) for 5-6h. A dAP-standard was analyzed along with the other samples for quantitation purposes.

\subsection{Western blots}

To study PCNA poly-ubiquitination upon BPDE-exposure, immunoblotting techniques were carried out as described previously [18]. Briefly, A549 and HeLa cells were treated with BPDE for $1 \mathrm{~h}$ and lysed $5 \mathrm{~h}$ post-treatment $(20 \mathrm{mM}$ Tris-HCl [pH 7.5], $150 \mathrm{mM} \mathrm{NaCl}, 1 \%$ Triton X-100, $2 \mathrm{mM}$ EDTA, and $5 \%$ glycerol with $200 \mu \mathrm{g} / \mathrm{ml}$ phenylmethylsulfonyl fluoride, $2 \mathrm{mM} \mathrm{NaVO}_{4}, 2 \mathrm{mM} \mathrm{NaF}$, and $2 \mathrm{mM} \mathrm{NaPPi}$ protease-inhibitor cocktail). Since, in our previous study UV was shown to induce poly-ubiquitination of PCNA [18], UVirradiated cells $\left(30 \mathrm{~J} / \mathrm{m}^{2}\right)$ were used as a positive control. Samples were sonicated, soluble fractions were recovered, and proteins were quantified. Proteins were resolved on a single-phase $10 \%$ SDS-polyacrylamide gel and electroblot- 
ted onto a Hybond C nitrocellulose membrane (Amersham Pharmacia Biotech, Piscataway, NJ, USA). The following antibodies were used: rabbit polyclonal anti-Ub (Dako, Glostrup, Denmark), mouse monoclonal anti-PCNA PC10 (Chemicon, http://www.chemicon.com), and mouse monoclonal antiactin (Sigma). Proteins were visualized using SuperSignal West Pico Chemiluminescent Substrate (Pierce Biotechnology, Rockford, IL, USA).

\subsection{Immunoprecipitations}

Immunoprecipitation of PCNA was performed as described previously [18]. In brief, cells were treated with BPDE as described above and harvested in lysis buffer. An anti-PCNA antibody was incubated overnight with $500 \mu \mathrm{g}$ of protein lysate. The following day, lysates were incubated with $100 \mu \mathrm{L}$ of Gamma-Bound Sepharose Beads (Amersham Pharmacia Biotech). After $48 \mathrm{~h}$ beads were washed extensively in lysis buffer, and proteins were eluted by boiling in Laemmli's SDS sample buffer. Immunoblotting was performed as described above except that the membranes were autoclaved for $20 \mathrm{~min}$ in $\mathrm{ddH}_{2} \mathrm{O}$ after protein transfer, and proteins were visualized as described above.

\subsection{GFP-POL $\eta$ foci formation}

A549 and HeLa cells stably expressing WT-Ub-puro and K63RUb-puro were grown on $35 \mathrm{~mm}$ glass bottom dishes (MatTek Corporation, Ashland, USA) until $80 \%$ confluency. Plasmids expressing POLn-GFP fusion protein (a generous gift of Dr. Alan R. Lehmann, Genome Damage and Stability Centre, University of Sussex, Falmer, Brighton, UK) were transfected into the cells using lipofectamine according to the manufacturer's protocol (Invitrogen Life Technologies, Carlsbad, CA). After $24 \mathrm{~h}$ of incubation, POL $\eta-G F P$ transfection efficiency was checked by fluorescence microscopy, and cells were exposed to 0.1 and $0.5 \mu \mathrm{M}$ BPDE for $30 \mathrm{~min}$ at $37^{\circ} \mathrm{C}$. Then $6 \mathrm{~h}$ post-incubation, cells expressing GFP-POL $\eta$ proteins were visualized using a live-cell microscopy unit mounted on a Leica DR IRBE inverted microscope, equipped with a polychromator that allows generation of light of the required wavelength, using a $63 \times$ magnification level. Both the polychromator and filterwheel were controlled via the PC using specialized Openlab software. To determine the percentage of

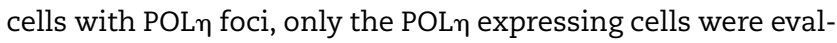
uated. At least 100 cells were counted for each experimental condition by an experienced and blinded observer.

For co-localization studies, WT-Ub-puro and K63R-Ubpuro expressing A549 cells were transiently transfected with a POL $\eta$-GFP plasmid in a chamber slide (BD Biosciences Pharmingen). Cells were exposed to 0.1 and $0.5 \mu \mathrm{M}$ BPDE (30 min at $37^{\circ} \mathrm{C}$ ), $24 \mathrm{~h}$ post-transfection. For detection of PCNA and POL $\eta$, cells were fixed in cold methanol for $20 \mathrm{~min}$ at $-20^{\circ} \mathrm{C}$ followed by $30 \mathrm{~s}$ in cold acetone to allow mild permeabilisation of the cells. Cells were washed twice with PBS and then incubated at room temperature with both antiPCNA and anti-POL $\eta$ antibodies. After $1 \mathrm{~h}$, cells were washed with PBS and then incubated with Alexa 488-conjugated goat anti-rabbit IgG (Invitrogen) and Texas red-conjugated goat anti-mouse (Invitrogen) secondary antibodies for $45 \mathrm{~min}$. After washing in PBS, cells were dehydrated for $1 \mathrm{~min}$ in $70 \%$ ethanol followed by two 1-min incubations in $100 \%$ ethanol. Cells were then mounted with Fluorescent Mounting Media (Dako) and visualized by two photon microscopy.

\subsection{Statistical analysis}

All data are presented as the mean \pm standard error of at least two independent experiments, unless stated otherwise. Differences in BPDE-DNA adduct removal and mutation frequencies between the different cell strains were analyzed by t-test. To examine differences in HPRT-mutation frequencies after exposure to various concentrations of BPDE versus the control (0 $\mu \mathrm{M}$ BPDE), one-way ANOVA was used with subsequent Dunnett's-correction for multiple comparisons. A non-parametric Mann-Whitney test was performed to analyze differences in POL $\eta$ foci formation between the two cell lines. Statistical analysis was performed using SPSS v.12.0.1. In each case, a difference was considered significant at $p<0.05$.

\section{Results}

\subsection{Disruption of K63-polyUb chain formation has no} effect on the sensitivity of transfected A549 cells to BPDE

To test the effect of disruption of K63-polyubiquitination on the sensitivity of transfected cells to BPDE, clonogenic survival assays were performed using a dose range from 0 to $1 \mu \mathrm{M} \mathrm{BPDE}$ (Fig. 1). We observed no statistical difference in the sensitivity of both cell lines to acute $(30 \mathrm{~min})$ treatment with BPDE. Similar observations were seen in mammalian [18] and yeast [15] cells demonstrating that expression of K63R-Ub does not affect the sensitivity towards UV. A possible explanation for the absence of a difference in sensitivity to acute BPDE exposure is that cells that are unable to form K63-polyUb chains can

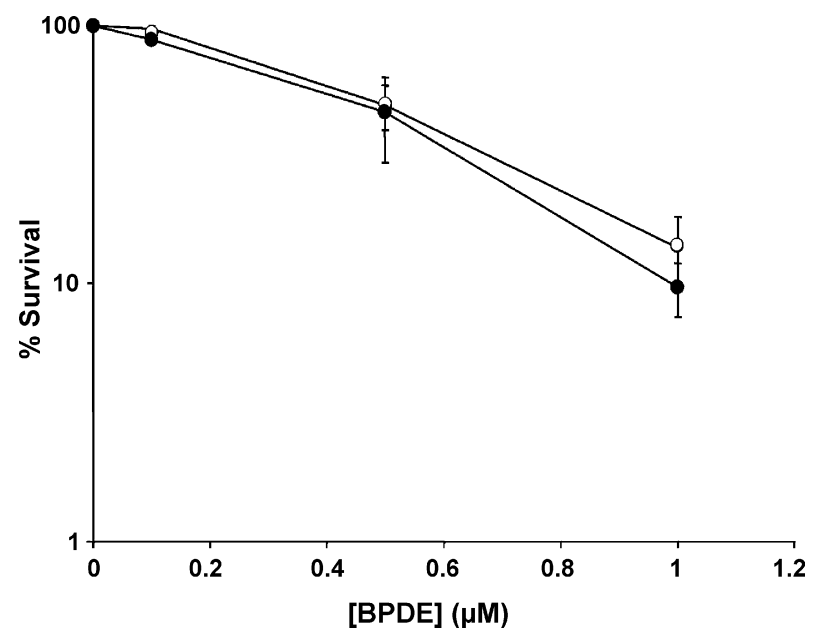

Fig. 1 - BPDE-induced cytotoxicity in A549 cells stably expressing K63R-Ub (O) or WT-Ub (O). Cells were exposed for $30 \mathrm{~min}$ to increasing concentrations of BPDE. Survival was evaluated by means of a clonogenic survival assay and expressed as the mean of three independent experiments (土S.E.). 
compensate for the loss of this pathway by utilizing the errorprone TLS arm of the DDT pathway. Therefore, these results suggest that inhibition of K63-polyUb chain formation does not sensitize cells to the toxic effect of BPDE indicating that WT-Ub and K63R-Ub expressing cells bypass BPDE-induced replication fork blockage with equal efficiency.

\subsection{Disruption of K63-polyUb chain formation}

enhances BPDE-induced HPRT-mutations and induces a characteristic mutation spectrum

To evaluate whether K63-polyUb chain disruption affects BPDE-induced mutagenesis, we determined the mutation frequency at the HPRT locus upon BPDE exposure. Following the correction for cell survival, A549 cells stably expressing K63R$\mathrm{Ub}$ showed a dose dependent and significant increase in the frequency of HPRT-mutations ( 54-, 87-, 19-fold increase at exposure levels of $0.1,0.5$ and $1 \mu \mathrm{M} \mathrm{BPDE}$, respectively) as compared to their WT-Ub expressing counterparts (Fig. 2). This increased BPDE-induced mutagenicity in the K63R-Ub expressing cells suggests that the formation of K63-polyUb chains is indeed a prerequisite for the error-free bypass of BPDE-DNA adducts.

Furthermore, we examined the spectrum of BPDE-induced mutations in individual clones of K63R-Ub expressing cells. Sister clones were excluded as only a single colony per treated population was isolated, as described above. Upon examination of the four overlapping sequences from each HPRT CDNA and removal of background mutations, 19 BPDEinduced mutations were found. Seventy-four percent of these mutations were $\mathrm{G} \rightarrow \mathrm{T}$ transversion, while $\mathrm{G} \rightarrow \mathrm{C}$ transitions accounted for $21 \%$ (Table 1 ). The large number of $G \rightarrow T$ mutations suggests that POL $\eta$ is the relevant mutagenic TLS

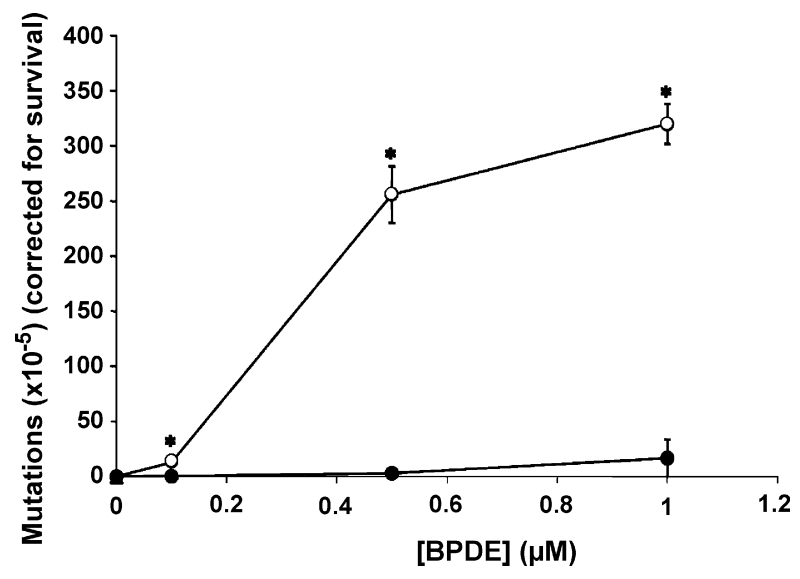

Fig. 2 - Effect of K63R-Ub expression on BPDE-induced mutagenicity. After exposure to BPDE, mutation frequencies at the HPRT gene were determined via selection in medium containing 6-TG. Mutations were corrected for survival and BPDE-induced mutation frequencies were obtained by subtracting the background frequencies, which were 0.59 and $10.37 \times 10^{-5}$ clonable cells for WT-Ub $(0)$ and $K 63 R-U b(O)$ expressing cells respectively. The mean values of two independent experiments are shown with standard errors ( $p<0.001, K 63 R-U b$ vs. WT-Ub).

polymerase (see Section 4). A single $\mathrm{T} \rightarrow \mathrm{G}$ mutation was unexpectedly observed suggesting that either the adenosine on the minus strand contained the BPDE adduct, or more likely, the mutation occurred as a result of misincorporation directly following a guanine adduct (see Table 1). Interestingly and in contrast to the previously reported UV-induced mutation

\section{Table 1 - BPDE-induced mutation spectrum in K63R-Ub expressing cells}

\begin{tabular}{|c|c|c|c|c|c|}
\hline Point mutations & Sequence change & Position (strand) & Amino acid & Mutant & Percentage of total \\
\hline$G>T$ & GATG $(G>$ T)TCAA & $472(+)$ & $\mathrm{Val} \rightarrow$ Phe & 1 & \\
\hline$G>T$ & GACA $(\mathrm{G}>\mathrm{T}) \mathrm{GACT}$ & $134(+)$ & $\mathrm{Arg} \rightarrow$ Met & 2 & \\
\hline$G>T$ & GGGG(G > T)GCTA & $212(+)$ & Gly $\rightarrow$ Cys & 5 & \\
\hline$G>T$ & ACAG(G > T)ACTG & $135(+)$ & Arg $\rightarrow$ Ser & 6 & \\
\hline$G>T$ & TGAT(G > T)AAGG & $162(+)$ & Met $\rightarrow$ lie & 7 & \\
\hline$G>T$ & GATG(G > T)TCAA & $472(+)$ & Val $\rightarrow$ Phe & 12 & \\
\hline$G>T$ & GTTG(G > T)ATTT & $539(+)$ & Gly $\rightarrow$ Val & 13,2 & \\
\hline$G>T$ & TCAA(G > T)GGGG & $207(+)$ & Lys $\rightarrow$ Asn & 14 & \\
\hline$G>T$ & GACT(G $>$ T)AACG & $139(+)$ & Glu $\rightarrow$ STOP & 17 & \\
\hline$G>T$ & CAGG(G > T)ATTT & $601(+)$ & Asp $\rightarrow$ Tyr & 19 & \\
\hline$G>T$ & ACTG $(G>T) A A A G$ & $380(+)$ & Gly $\rightarrow$ Val & 20 & \\
\hline$G>T$ & ACAG $(G>T) G G A C$ & $335(+)$ & Gly $\rightarrow$ Val & 21,2 & \\
\hline$G>T$ & TCAA(G > T)GGGG & $207(+)$ & Lys $\rightarrow$ Asn & 24 & \\
\hline$G>T$ & AAGT(G > T)TTGG & $514(+)$ & Val $\rightarrow$ Phe & 28 & 74 \\
\hline$G>C$ & GAAC $(\mathrm{G}>\mathrm{C}) \mathrm{TCTT}$ & $143(+)$ & Arg $\rightarrow$ Pro & 10 & \\
\hline$G>C$ & TCAA $(G>C) G G G G$ & $207(+)$ & Lys $\rightarrow$ Asn & 11 & \\
\hline$G>C$ & TAAT $(G>C)$ ACCA & $322(+)$ & Asp $\rightarrow$ His & 13,1 & \\
\hline$G>C$ & GACT $(G>C) A A C G$ & $139(+)$ & Glu $\rightarrow$ Gln & 21,1 & 21 \\
\hline $\mathrm{T}>\mathrm{G}$ & AAGG $(T>G) C G C A$ & $479(+)$ & $\mathrm{Val} \rightarrow$ Gly & 4 & 5 \\
\hline
\end{tabular}

A549 cells stably expressing K63R-Ub were exposed to $0.5 \mu \mathrm{M}$ BPDE, further cultured for 7 days and then seeded in medium containing 6-TG. Single colonies were picked from each dish to ensure that no sister clones would be analyzed. The HPRT gene was then amplified by PCR followed by sequencing using four overlapping primers. The mutants are grouped by the type of observed point mutations. 
spectra [18], most of the BPDE-induced base substitutions had the guanine adduct on the non-transcribed (+) strand. These data are consistent with the mutation spectrum of BPDEtreated human fibroblasts or T-lymphocyte clones that were conducted in other studies [22,23]. Collectively, these data suggest that inhibition of K63-polyUb chain assembly results in an increased mutagenic effect of BPDE-exposure, indicating the involvement of error-prone TLS.

\subsection{Disruption of K63-polyUb chain formation does not affect the occurrence and repair of BPDE-DNA adducts}

Mutagenicity of BPDE is directly related to the number of BPDE-DNA adducts in the cell $[22,24]$. Therefore, to exclude the possibility that the distinct mutagenic effects of BPDE in K63R-Ub versus WT-Ub transfected cells as described above, could be explained by either different initial BPDE-DNA adduct levels, or differences in time-dependent adduct removal, we evaluated the kinetics of BPDE-DNA adduct levels over a period of $24 \mathrm{~h}$ by ${ }^{32} \mathrm{P}$-postlabeling. Representative DNA adduct profiles of both $\mathrm{A} 549$ cell lines, acutely exposed to $0.1 \mu \mathrm{M}$ BPDE, are shown in Fig. 3(insert). For both the WT-Ub and K63R-Ub expressing cells, clear BPDE-dG spots were observed after a $30 \mathrm{~min}$ incubation period $(t=0 \mathrm{~h})$. The intensity of the $( \pm)$-anti-BPDE-dG spots rapidly reduced in time, indicating effective removal of the BPDE-DNA adducts. Quantitative analysis revealed that the initial adduct level caused by acute treatment with $0.1 \mu \mathrm{M}$ was similar between both cell lines $\left(32.9 \pm 4.8\right.$ and $31.6 \pm 6.9$ adducts $/ 10^{8}$ nucleotides for WT-Ub and K63R-Ub expressing cells, respectively). Moreover, no significant differences $(p>0.5)$ in removal of BPDE-DNA adducts

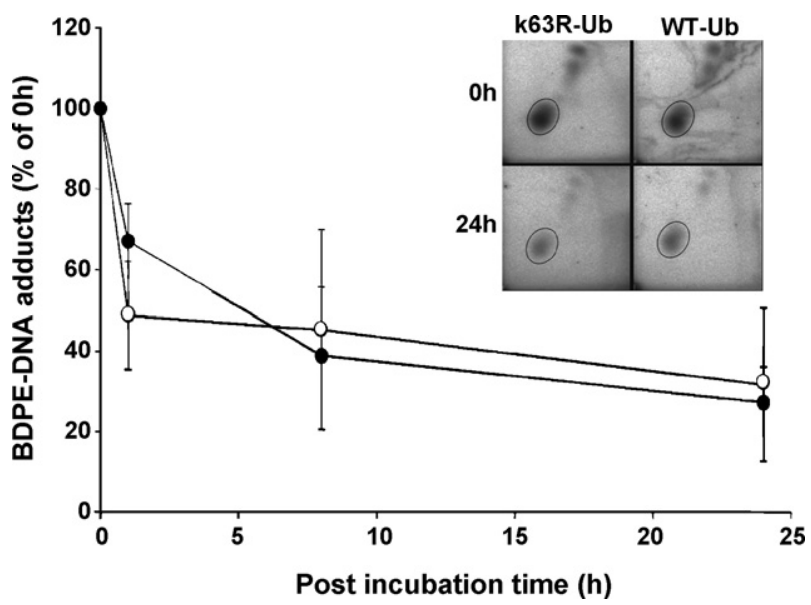

Fig. 3 - Removal of ( $\left( \pm\right.$ )-anti-BPDE-N2 ${ }^{2}$-dG adducts in WT-Ub $(\odot)$ and K63R-Ub $(O)$ expressing A549 cells after acute exposure to $0.1 \mu \mathrm{M}$ BPDE. Chromatograms of ${ }^{32} \mathrm{P}$-labeled BPDE-DNA adducts. A549 cell strains stably expressing K63R-Ub and WT-Ub show clear spots immediately after exposure to BPDE (Insert). After recovery of $24 \mathrm{~h}$ spot-intensities were reduced. Quantification was performed on the circled spots, which represent the $( \pm)$-anti-BPDE- $N^{2}$-dG adducts. ( \pm -)-anti-BPDE-DNA adduct removal in A549 cells strains at various time intervals. Data are expressed as the mean adduct levels of two independent experiments ( \pm S.E.). were observed between A549 cells stably expressing K63R-Ub or WT-Ub (Fig. 3). In both cell lines, DNA-adduct levels are reduced by $50 \%$ within $8 \mathrm{~h}$. To correct for possible dilution effects on DNA-adduct levels due to DNA synthesis during cell replication, adduct levels were corrected for cell proliferation for each time point (\# cells at $t=$ recovery/\# cells at $t=0 \mathrm{~h}$ ). Overall, these data suggest that the NER capacities of both A549 cell strains are comparable, and that NER is not affected by genetic modification of the Lys63-poly-ubiquitination process.

\subsection{BPDE induces PCNA poly-ubiquitination}

Thus far, our data support the idea that K63-linked ubiquitin chains are critical in the recovery of replication forks after the production of BPDE-induced DNA damage. Based on our previous study [18], we postulated that the likely substrate of these chains is PCNA. Other studies have shown that BPDE exposure leads to mono-ubiquitination of PCNA [25] while PCNA poly-ubiquitination has not previously been reported. We investigated whether PCNA is poly-ubiquitinated in mammalian cells after BPDE treatment. Both A549 and HeLa cells were treated with 0.5 or $1 \mu \mathrm{M}$ BPDE or $30 \mathrm{~J} / \mathrm{m}^{2} \mathrm{UVB}$ as a positive control. Five hours post-treatment, a prominent mono-ubiquitinated and a faint di-ubiquitinated band was observed in both UV and BPDE treated cells (Fig. 4A). In addition, over-exposure of this blot revealed a stronger higher molecular weight band corresponding to di-ubiquitinated PCNA. Similar to our previous report using UV light as a mode of DNA damage, it is often difficult to see more than a diubiquitinated form of PCNA on an immunoblot after DNA damage, which is a likely limitation of the antibody. In addition, we also see lower levels of mono- and di-Ub PCNA in our untreated cells. We postulate that this modification is a response to endogenous DNA damage.

Nevertheless, to confirm that these bands are indeed ubiquitinated PCNA, immunoprecipitation using an antibody directed against PCNA followed by immunoblotting with anti-ubiquitin was performed (Fig. 4B). Several ubiquitinated species were observed corresponding to mono-, di-, tri- and tetra-ubiquitinated PCNA. This laddering pattern was similar to the banding pattern observed after UV irradiation from a previous study [18]. Taken together, our data suggest that PCNA is a target for poly-ubiquitination after BPDE-induced DNA damage, further supplementing the accumulating evidence that PCNA poly-ubiquitination is an important process in response to a variety of DNA lesions.

\subsection{Increased recruitment of POL $\eta$ to the replication fork upon blockage by BPDE}

To support our suggestion that the increased BPDE mutagenesis in the K63R-Ub expressing cells is brought about by the enhanced recruitment of error-prone Y-family polymerases, we analyzed the effects of K63R-Ub expression on POL $\eta$ foci formation. We selected this particular TLS polymerase as previous reports suggest that it is the relevant polymerase responsible for the error-prone bypass of BPDE-DNA adducts $[9,11]$. The previously described HeLa and A549 cells, expressing WT-Ub or K63R-Ub fused with the puromycin resistance

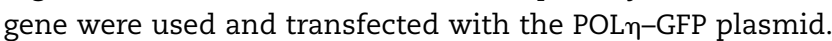


(A)
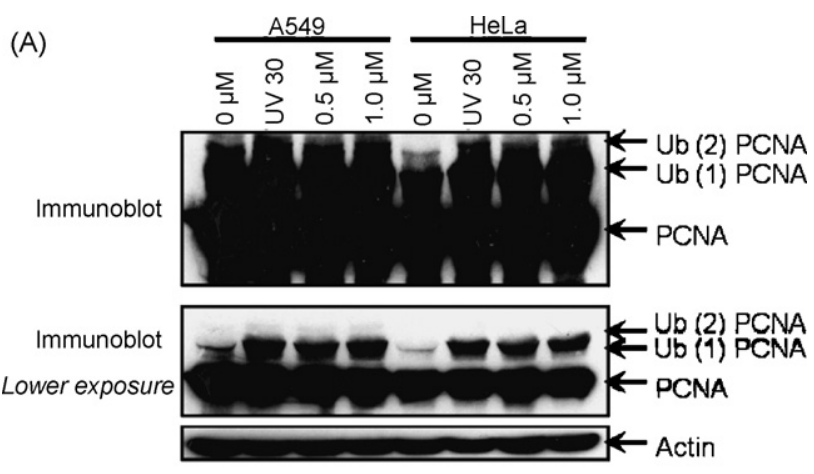

(B)
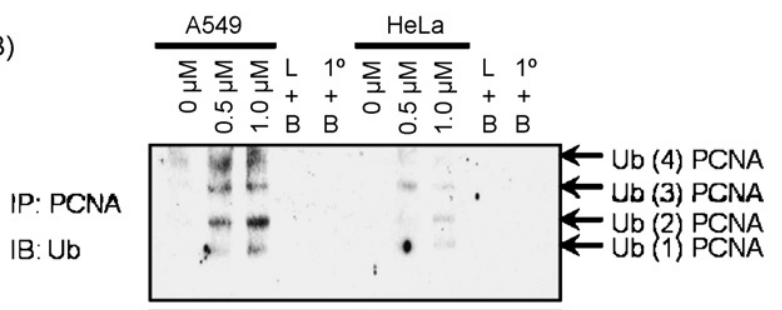

IP: PCNA

IB: PCNA

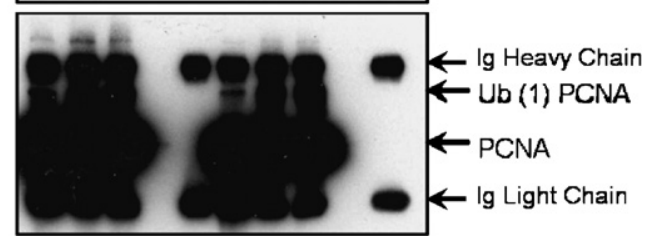

Fig. 4 - Poly-ubiquitination of PCNA upon UV- and

BPDE-exposure. (A) Immunoblot from A549 and HeLa cells that were irradiated with $30 \mathrm{~J} / \mathrm{m}^{2} \mathrm{UV}$ or exposed to 0.5 and $1 \mu \mathrm{M}$ BPDE. Cells were lysed $6 \mathrm{~h}$ post-treatment followed by immunoblotting for PCNA. A high and lower exposure of the PCNA immunoblot is shown. (B) A549 cells were exposed to BPDE and lysed in boiling SDS, diluted in lysis buffer and subjected to immunoprecipitation with a PCNA antibody and detected with PCNA or Ub antibodies. The controls in the immunoprecipitations were " $\mathrm{L}+\mathrm{B}$ ", in which lysates were incubated with beads but no PCNA antibody, and " $1^{\circ}+\mathrm{B}$ " in which PCNA antibody was incubated with beads alone. In the latter case only the immunoglobulin heavy and light chains are detected on the immunoprecipitations.

No differences in transfection efficiency with POL $\eta-G F P$ in both cell lines were observed (data not shown). Importantly, we previously showed that these cells behave identically to the ubiquitin GFP fusion expressing cells and that there were no overt defects in POLn function [18]. In line with other similar studies [26], we observed homogenous nuclear expression of the POLn protein in all transfected cells. Similar to previous reports $[18,26-28]$, in the absence of $\mathrm{BPDE}$, foci were observed in $17 \%$ and $22 \%$ of the HeLa cells (Fig. 5A) and $14 \%$ and $15 \%$ of the A549 cells (Fig. 5B) expressing WT-Ub or K63R$\mathrm{Ub}$, respectively, showing no statistical differences between both cell lines. Within $6 \mathrm{~h}$ after exposure to 0.1 and $0.5 \mu \mathrm{M}$ BPDE, POL $\eta$ relocalized in distinct focal patterns in the nucleus (Fig. 5C, left). Upon exposure to $0.5 \mu \mathrm{M}$ BPDE, the percentage of cells with foci increased to $52.5 \%$ and $53.9 \%$ in HeLa and A549 cells expressing K63R-Ub, respectively (Fig. 5A and B). In
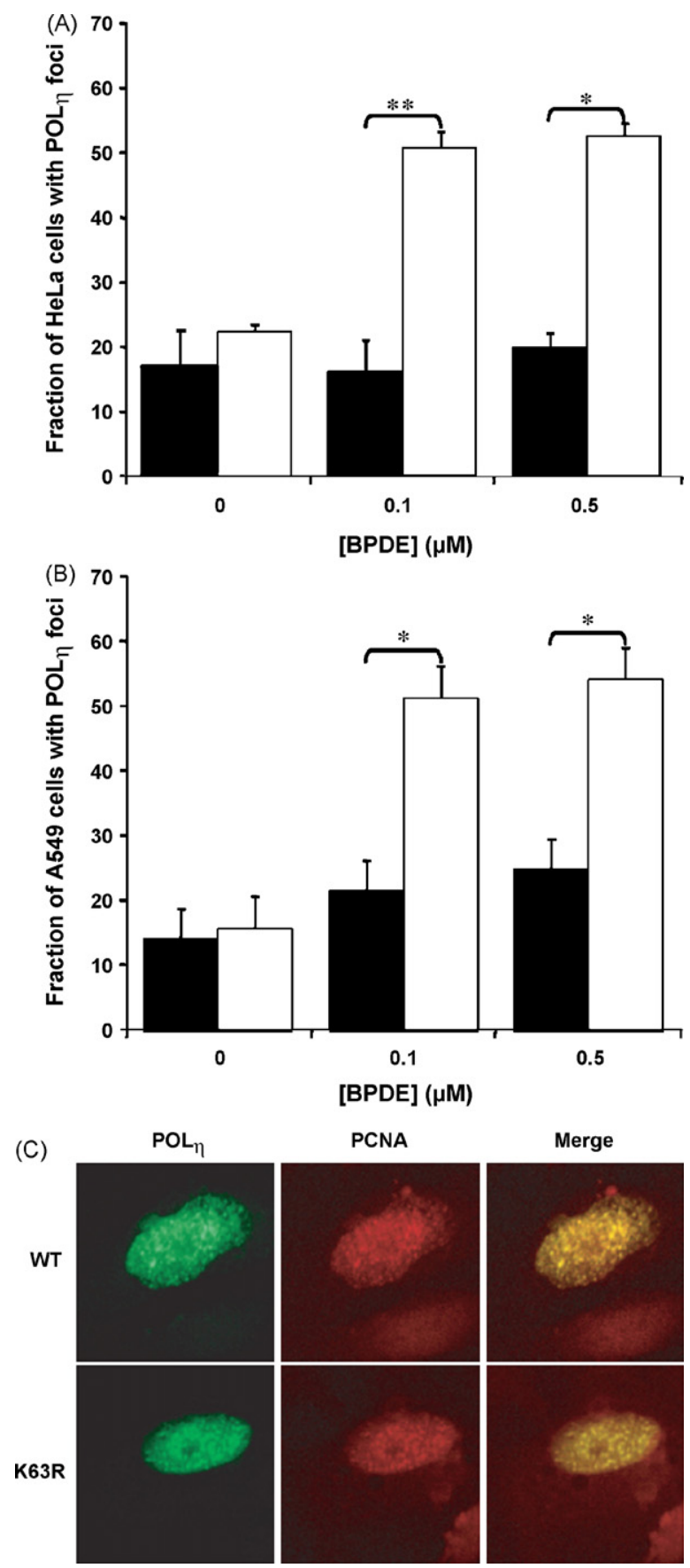

Fig. 5 - Relocalization of POL $\eta$ into intranuclear foci after BPDE-exposure. (A) HeLa cells $(n=4)$ and (B) A549 cells $(n=2)$ stably expressing WT-Ub-puro $(\square)$ and K63R-Ub-puro $(\square)$ were transiently transfected with plasmids encoding GFP-POLn. Twenty-four hours post-transfection, cells were exposed to 0.1 and $0.5 \mu \mathrm{M}$ BPDE for $30 \mathrm{~min}$ at $37^{\circ} \mathrm{C}$. Foci were quantified $6 \mathrm{~h}$ after treatment using a live-cell imaging microscope and percentages of cells with POL $\eta$ foci were calculated. The mean values of at least two independent experiments are shown with standard error $\left({ }^{* *} p=0.02\right.$, " $p<0.05 \mathrm{~K} 63 \mathrm{R}-\mathrm{Ub}$ vs. WT-Ub for 0.1 and $0.5 \mu \mathrm{M}$ BPDE, respectively). (C) Representative confocal photographs showing a $100 \%$ co-localization of POL $\eta$ with PCNA in A549 cells, $6 \mathrm{~h}$ after BPDE-exposure. POL $\eta$ (green) and PCNA (red) were detected using antibodies. 
HeLa and A549 cells stably expressing WT-Ub, the induction of POL $\eta$ foci was significantly less after BPDE-exposure $(20 \%$ and $25 \%$ at $0.5 \mu \mathrm{M}$ of BPDE for HeLa and A549 cells, respectively). Overall, our data show that inhibition of K63-linked polyubiquitination causes an approximately three-fold increase in POL $\eta$ foci $(p<0.05)$ after acute exposure to BPDE. This increase parallels the enhanced mutation frequency in BPDE-treated K63R-Ub expressing cells (Fig. 2) suggesting the involvement of POL $\eta$ in BPDE-induced mutagenesis in the K63R-Ub expressing cells. Furthermore, we also analyzed the co-localization of these foci with sites of DNA replication as revealed by positive PCNA foci. In both the WT-Ub and K63R-Ub expressing A549 cells, $100 \%$ of the BPDE-induced POLn foci co-localized with PCNA foci (Fig. 5C). This indicates that the foci produced in the K63R-Ub expressing cells are typical of those previously reported to occur at sites of blocked replication $[18,26]$.

\subsection{Knockdown of POL $\eta$ diminishes the mutagenicity of BPDE}

Collectively, our data suggest that inhibition of K63-polyUb chain assembly results in an increased requirement for TLS to bypass BPDE-DNA adducts (cf. Fig. 5). To establish a possible

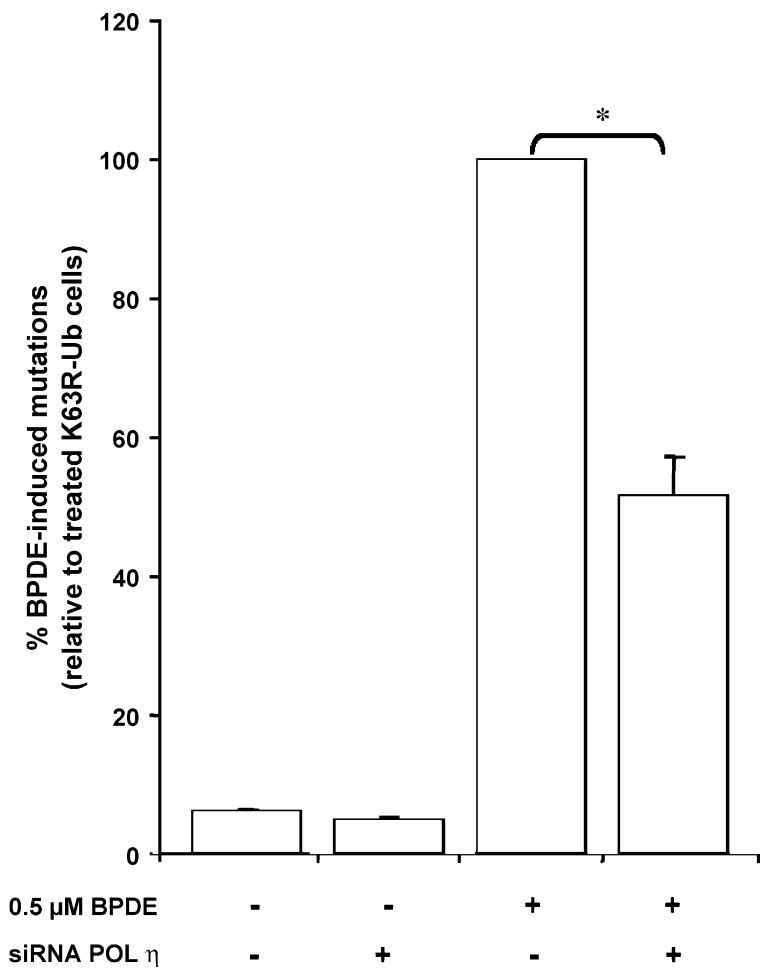

Fig. 6 - Effect of POL $\eta$ knockdown on BPDE-induced mutagenicity. The number of HPRT mutants was quantitated upon exposure to $0.5 \mu \mathrm{M}$ BPDE for A549 cells

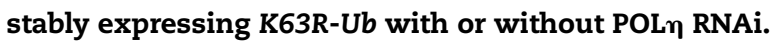
BPDE-induced mutations were corrected for the plating efficiency and presented as the percentages of the mutation frequency in the BPDE treated K63R-Ub expressing cells. The mean values of two independent experiments are shown with standard error $(p<0.03$, BPDE exposed cells with vs. without POL $\eta$ RNAi). causal role of POL $\eta$ in the increased mutagenicity of BPDE as observed in the K63R-Ub expressing cells, we suppressed the expression of POL $\eta$ in these cells by using siRNA. The combination of disrupting K63R-polyUb chain formation and POLn knockdown resulted in a $50 \%$ reduction in BPDE-induced HPRT mutations (Fig. 6), indicating a predominant role of POL $\eta$ in error-prone bypass of BPDE lesions in the K63R-Ub expressing cells.

\section{Discussion}

In the present study we showed that lysine 63-linked polyubiquitination is an important process to protect mammalian cells against BPDE-induced mutagenicity. This protective effect is distinct from TLS and is likely caused by directing DDT mechanisms into an error-free pathway, in which the information on the daughter strand is used to correctly circumvent the DNA lesion. This would suggest that K63-poly-ubiquitination is a general requirement for physiological protection against mutagenesis in mammalian cells.

Stelter and Ulrich have shown that disruption of the errorfree arm of DDT in yeast, as a consequence of a UBC13 mutation, results in a dramatic increase in UV-induced mutations [15]. Moreover, we recently reported that K63-linked poly-ubiquitination is required for error-free DDT in human cells as disruption of this specific chain formation leads to increased UV mutagenicity $[18,29]$. In the present study, K63linked poly-ubiquitination was observed upon exposure to BPDE and inhibition of this polyUb chain formation resulted in up to 87-fold increase in BPDE-induced mutations in $\mathrm{K} 63 \mathrm{R}-\mathrm{Ub}$ compared to the WT-Ub expressing cells.

In a previous study we proposed a model in which K63-polyUb chains are suggested to activate an error-free mechanism that protects cells against UV-induced mutations that would otherwise be induced by error-prone TLS polymerases [18]. In this present study, we extend this model to include the bypass of BPDE-DNA lesions implying that the observed increased BPDE-induced mutation frequency in the K63R-Ub expressing cells would likely be caused by low-fidelity and error-prone DNA polymerases. Previous reports have suggested that POL $\eta$ is the main polymerase responsible for the mutagenicity of BPDE-DNA adducts by predominantly inserting an adenosine opposite the BPDE- $\mathrm{N}^{2}$ $\mathrm{dG}$ lesion, causing the characteristic $\mathrm{G} \rightarrow \mathrm{T}$ transversions [9]. Appropriately, the majority (74\%) of mutations observed in our model is also this $\mathrm{G} \rightarrow \mathrm{T}$ mutation supporting the idea that POL $\eta$ is the relevant enzyme for the bypass of BPDE-DNA adducts. Furthermore, intra-nuclear POLn foci formation was approximately three-fold increased in BPDE-treated K63R-Ub expressing cells, indicating the involvement of POL $\eta$ in the increased BPDE-induced mutagenic effects in absence of K63linked poly-ubiquitination. In the HeLa and A549 cells stably expressing WT-Ub there was no clear induction of cells with POL $\eta$ foci after BPDE-exposure. This is in contrast with studies from Ogi et al. observing POL $\eta$ foci recruitment in 90\% of the human lung fibroblast exposed to $20 \mu \mathrm{M}$ of $\mathrm{B}[\mathrm{a}] \mathrm{P}$ [27]. These contrasting observations are most likely explained by a significant difference in dosing strategies. In the present study POL $\eta$ foci were assessed $6 \mathrm{~h}$ post-acute $(30 \mathrm{~min}$ ) BPDE treatment, while Ogi et al. quantitated foci following $16 \mathrm{~h}$ of contin- 
uous exposure to complete medium containing $\mathrm{B}[\mathrm{a}] \mathrm{P}$ and S9 mix.

We observed POLn foci to co-localize with the DNA polymerase clamp, PCNA. As this protein is required for replication, this suggests that POL $\eta$ is tightly associated with the replication machinery and is therefore locally available to carry out TLS past the blocking lesions. Similar POL $\eta$ recruitment and co-localizations were observed in human fibroblasts $[26,30]$ and human cancer cell lines [18] upon exposure to UV irradiation. Furthermore, we studied the effect of POL $\eta$ knockdown on the BPDE-induced mutation frequencies in the K63R-Ub expressing A549 cells, and found a 50\% reduction in HPRT mutations. This further confirms that POL $\eta$ is a crucial component of the error-prone bypassing of replication stalling BPDE-DNA adducts in cells with suppressed K63-linked polyubiquitination.

The preferential insertion of adenosine by POL $\eta$ opposite $\left( \pm\right.$ )-anti-BPDE- $N^{2}-d G$ adducts will lead to the induction of G:C to T:A transversions [9]. This was indeed confirmed by analyzing the mutation spectrum in the BPDE-treated K63R-Ub expressing cells, showing predominantly $\mathrm{G} \rightarrow \mathrm{T}$ point mutations. An intriguing explanation for the increase in mutation frequency and the high proportion of G:C-to-T:A transversions is the relative resistance of especially the (+)-trans-anti-BPDE$\mathrm{N}^{2}$-dG adducts to NER due to its minimal distortion of the helix [31]. As a consequence of this adduct being silent to NER, we predict that these adducts will persist over time and thus present as a substrate for POLn mediated mutagenesis. Intriguingly, this would suggest that known helix deforming lesions such as those produced by UV light would be less mutagenic than BPDE. Indeed, UV-induced mutation frequency in this model system was previously reported to be 2-fold increased [18] compared to 87-fold for 0.5 $\mu \mathrm{M}$ BPDE. Since UV-induced DNA lesions cause severe DNA-helix distortions that will be repaired faster by NER [31,32], reliance on potentially mutagenic TLS-bypass processes during replication will be attenuated.

Interestingly, all observed $\mathrm{G} \rightarrow \mathrm{T}$ transversions were consistent with a BPDE-guanine adduct on the non-transcribed (+) strand of the HPRT gene that was replicated inaccurately. As previously reported, this strand specificity indicates preferential repair of BPDE-DNA adducts in the transcribed strand, which is consistently faster than the repair of adducts in the non-transcribed strand $[23,33]$. The transcription coupled repair sub-pathway of NER is highly selective for adducts in the transcribed DNA strand [34,35], whereas repair of the non-transcribed strand will be dependent on DNA replication across these 'bulky' DNA adducts by TLS. This suggests that cells that contain lesions that are less amenable to NER would rely more on bypass by TLS as a means for survival. Interestingly, this would predict that lesions on the non-transcribed strand would persist and remain in the genome.

$\mathrm{G}: \mathrm{C}$ to T:A transversions are also found in higher frequencies in lung cancers from smokers compared to non-smokers [36]. Moreover, others have shown a good correlation between hotspots of DNA adduct formation by PAHs, such as $\mathrm{B}[\mathrm{a}] \mathrm{P}$, found in tobacco smoke and G:C to T:A transversion hotspots in lung cancer [37]. This higher prevalence of $\mathrm{G} \rightarrow \mathrm{T}$ transversions in lung cancer is generally interpreted as the primary mutagenic signature of PAH-DNA damage. As such, it would be of great interest to determine whether Lys63-polyUb chain formation has an etiological role in tobacco smoke-induced and $\mathrm{PAH}$-mediated lung cancer. Studies of Sasaki et al. for instance [38], showed a link between lung cancer and the RAD6dependent DDT mechanisms. They observed a decreased expression of the human homologue of yeast RAD6 (hRAD6B) in lung cancer, which might be a biomarker for decreased DDT capacity. Since, RAD6 is one of the key players in the enzymatic complex (RAD18, RAD5, UBC13/MMS2) that assembles the K63R-polyUb chains [14], this may suggest a link between pulmonary carcinogenesis and K63R-polyUb chain formation.

In conclusion, our data show that inhibition of Lys63-linked poly-ubiquitination of PCNA significantly enhances BPDEinduced mutations involving recruitment of the error-prone Y-family polymerase POLn. We therefore propose that formation of K63-polyUb chains protects (BPDE-exposed) human cells against translesion synthesis-mediated mutagenesis, implying that ubiquitination guards against chemical carcinogenesis. This predicts that alterations in ubiquitination and the genes that control it may influence the susceptibility of individuals to environmental mutagenesis, and possibly carcinogenesis. For example, it has been demonstrated that oxidative stress modulates the ubiquitination process via reversible $\mathrm{S}$ thiolation/dethiolation of E1 and E2 enzymes [39-41]. Such an effect could have major consequences for functioning of ubiquitin-conjugating enzymes (E2s), such as RAD6 and UBC13, and thus Lys63-linked poly-ubiquitination. Finally, a major challenge for future studies will be to further elucidate DDT pathways in humans and to appreciate their role in cancer development upon exposure to environmental xenobiotics. Such studies should reveal whether K63-polyUb chain formation could serve as a target for chemopreventive strategies.

\section{Acknowledgements}

We are thankful to the laboratory of Dr. Alan R. Lehmann (Genome Damage and Stability Centre, University of Sussex, Falmer, Brighton, UK) for providing plasmids expressing POLn-GFP fusion protein. This work was partially supported by the Dutch Cancer Society (grant \# UM2002-2636). A.M. Knaapen was supported by a postdoctoral fellowship from The Netherlands Organisation for Scientific Research (NWO, grant 916.46.092). Furthermore, we thank Ralph W.H. Gottschalk for HPRT DNA sequencing and Kim Douma for two-photon fluorescence microscopy.

\section{REFEREN CES}

[1] D.H. Phillips, Fifty years of benzo(a)pyrene, Nature 303 (1983) 468-472.

[2] K. Peltonen, A. Dipple, Polycyclic aromatic hydrocarbons: chemistry of DNA adduct formation, J. Occup. Environ. Med. 37 (1995) 52-58.

[3] S.C. Cheng, B.D. Hilton, J.M. Roman, A. Dipple, DNA adducts from carcinogenic and noncarcinogenic enantiomers of benzo[a]pyrene dihydrodiol epoxide, Chem. Res. Toxicol. 2 (1989) 334-340. 
[4] M. Moriya, S. Spiegel, A. Fernandes, S. Amin, T. Liu, N. Geacintov, A.P. Grollman, Fidelity of translesional synthesis past benzo[a]pyrene diol epoxide-2'-deoxyguanosine DNA adducts: marked effects of host cell, sequence context, and chirality, Biochemistry 35 (1996) 16646-16651.

[5] S. Broomfield, T. Hryciw, W. Xiao, DNA postreplication repair and mutagenesis in Saccharomyces cerevisiae, Mutat. Res. 486 (2001) 167-184.

[6] Z. Wang, DNA damage-induced mutagenesis: a novel target for cancer prevention, Mol. Interv. 1 (2001) 269-281.

[7] E.C. Friedberg, A.R. Lehmann, R.P. Fuchs, Trading places: how do DNA polymerases switch during translesion DNA synthesis? Mol. Cell. 18 (2005) 499-505.

[8] T. Ogi, Y. Shinkai, K. Tanaka, H. Ohmori, Polkappa protects mammalian cells against the lethal and mutagenic effects of benzo[a]pyrene, Proc. Natl. Acad. Sci. U.S.A. 99 (2002) 15548-15553.

[9] Y. Zhang, X. Wu, D. Guo, O. Rechkoblit, N.E. Geacintov, Z. Wang, Two-step error-prone bypass of the (+)- and (-)-trans-anti-BPDE- ${ }^{2}-\mathrm{dG}$ adducts by human DNA polymerases eta and kappa, Mutat. Res. 510 (2002) 23-35.

[10] A.R. Lehmann, Replication of damaged DNA by translesion synthesis in human cells, FEBS Lett. 579 (2005) 873-876.

[11] O. Rechkoblit, Y. Zhang, D. Guo, Z. Wang, S. Amin, J. Krzeminsky, N. Louneva, N.E. Geacintov, Trans-Lesion synthesis past bulky benzo[a]pyrene diol epoxide N2-dG and N6-dA lesions catalyzed by DNA bypass polymerases, J. Biol. Chem. 277 (2002) 30488-30494.

[12] C. Hoege, B. Pfander, G.L. Moldovan, G. Pyrowolakis, S. Jentsch, RAD6-dependent DNA repair is linked to modification of PCNA by ubiquitin and SUMO, Nature 419 (2002) 135-141.

[13] R.M. Hofmann, C.M. Pickart, Noncanonical MMS2-encoded ubiquitin-conjugating enzyme functions in assembly of novel polyubiquitin chains for DNA repair, Cell 96 (1999) 645-653.

[14] J. Spence, S. Sadis, A.L. Haas, D. Finley, A ubiquitin mutant with specific defects in DNA repair and multiubiquitination, Mol. Cell Biol. 15 (1995) 1265-1273.

[15] P. Stelter, H.D. Ulrich, Control of spontaneous and damage-induced mutagenesis by SUMO and ubiquitin conjugation, Nature 425 (2003) 188-191.

[16] C.A. Leach, W.M. Michael, Ubiquitin/SUMO modification of PCNA promotes replication fork progression in Xenopus laevis egg extracts, J. Cell Biol. 171 (2005) 947-954.

[17] P.L. Kannouche, J. Wing, A.R. Lehmann, Interaction of human DNA polymerase eta with monoubiquitinated PCNA: a possible mechanism for the polymerase switch in response to DNA damage, Mol. Cell 14 (2004) 491-500.

[18] R.K. Chiu, J. Brun, C. Ramaekers, J. Theys, L. Weng, P. Lambin, D.A. Gray, B.G. Wouters, Lysine 63-polyubiquitination guards against translesion synthesis-induced mutations, PLoS Genet. 2 (2006) e116.

[19] M. Tsirigotis, M. Zhang, R.K. Chiu, B.G. Wouters, D.A. Gray, Sensitivity of mammalian cells expressing mutant ubiquitin to protein-damaging agents, J. Biol. Chem. 276 (2001) 46073-46078.

[20] F.J. van Schooten, M.J. Hillebrand, E. Scherer, L. den Engelse, E. Kriek, Immunocytochemical visualization of DNA adducts in mouse tissues and human white blood cells following treatment with benzo[a]pyrene or its diol epoxide. A quantitative approach, Carcinogenesis 12 (1991) 427-433.

[21] R.W. Godschalk, L.M. Maas, N. Van Zandwijk, L.J. van't Veer, A. Breedijk, P.J. Borm, J. Verhaert, J.C. Kleinjans, F.J. van Schooten, Differences in aromatic-DNA adduct levels between alveolar macrophages and subpopulations of white blood cells from smokers, Carcinogenesis 19 (1998) 819-825.

[22] Z. Li, H. Zhang, T.P. McManus, J.J. McCormick, C.W. Lawrence, V.M. Maher, hREV3 is essential for error-prone translesion synthesis past UV or benzo[a]pyrene diol epoxide-induced DNA lesions in human fibroblasts, Mutat. Res. 510 (2002) 71-80.

[23] B. Andersson, S. Falt, B. Lambert, Strand specificity for mutations induced by (+)-anti BPDE in the hprt gene in human T-lymphocytes, Mutat. Res. 269 (1992) 129-140.

[24] W.G. McGregor, D. Wei, R.H. Chen, V.M. Maher, J.J. McCormick, Relationship between adduct formation, rates of excision repair and the cytotoxic and mutagenic effects of structurally-related polycyclic aromatic carcinogens, Mutat. Res. 376 (1997) 143-152.

[25] X. Bi, L.R. Barkley, D.M. Slater, S. Tateishi, M. Yamaizumi, H. Ohmori, C. Vaziri, Rad18 regulates DNA polymerase kappa and is required for recovery from S-phase checkpoint-mediated arrest, Mol. Cell Biol. 26 (2006) 3527-3540.

[26] P. Kannouche, B.C. Broughton, M. Volker, F. Hanaoka, L.H. Mullenders, A.R. Lehmann, Domain structure, localization, and function of DNA polymerase eta, defective in xeroderma pigmentosum variant cells, Genes Dev. 15 (2001) 158-172.

[27] T. Ogi, P. Kannouche, A.R. Lehmann, Localisation of human Y-family DNA polymerase kappa: relationship to PCNA foci, J. Cell Sci. 118 (2005) 129-136.

[28] X. Bi, D.M. Slater, H. Ohmori, C. Vaziri, DNA polymerase kappa is specifically required for recovery from the benzo[a]pyrene-dihydrodiol epoxide (BPDE)-induced S-phase checkpoint, J. Biol. Chem. 280 (2005) 22343-22355.

[29] Z. Li, W. Xiao, J.J. McCormick, V.M. Maher, Identification of a protein essential for a major pathway used by human cells to avoid UV-induced DNA damage, Proc. Natl. Acad. Sci. U.S.A. 99 (2002) 4459-4464

[30] K. Watanabe, S. Tateishi, M. Kawasuji, T. Tsurimoto, H. Inoue, M. Yamaizumi, Rad18 guides poleta to replication stalling sites through physical interaction and PCNA monoubiquitination, EMBO J. 23 (2004) 3886-3896.

[31] M.T. Hess, D. Gunz, N. Luneva, N.E. Geacintov, H. Naegeli, Base pair conformation-dependent excision of benzo[a]pyrene diol epoxide-guanine adducts by human nucleotide excision repair enzymes, Mol. Cell Biol. 17 (1997) 7069-7076.

[32] A. Luch, Nature and nurture-lessons from chemical carcinogenesis, Nat. Rev. Cancer 5 (2005) 113-125.

[33] M.F. Denissenko, A. Pao, G.P. Pfeifer, M. Tang, Slow repair of bulky DNA adducts along the nontranscribed strand of the human p53 gene may explain the strand bias of transversion mutations in cancers, Oncogene 16 (1998) 1241-1247.

[34] P.C. Hanawalt, B.A. Donahue, K.S. Sweder, Repair and transcription. Collision or collusion? Curr. Biol. 4 (1994) 518-521.

[35] J.R. Mitchell, J.H. Hoeijmakers, L.J. Niedernhofer, Divide and conquer: nucleotide excision repair battles cancer and ageing, Curr. Opin. Cell Biol. 15 (2003) 232-240.

[36] F. Le Calvez, A. Mukeria, J.D. Hunt, O. Kelm, R.J. Hung, P. Taniere, P. Brennan, P. Boffetta, D.G. Zaridze, P. Hainaut, TP53 and KRAS mutation load and types in lung cancers in relation to tobacco smoke: distinct patterns in never, former, and current smokers, Cancer Res. 65 (2005) 5076-5083.

[37] M.F. Denissenko, A. Pao, M. Tang, G.P. Pfeifer, Preferential formation of benzo[a]pyrene adducts at lung cancer mutational hotspots in P53, Science 274 (1996) 430-432.

[38] H. Sasaki, S. Moriyama, Y. Nakashima, H. Yukiue, I. Fukai, Y. Fujii, Decreased Hrad6B expression in lung cancer, Acta Oncol. 43 (2004) 585-589. 
[39] J. Jahngen-Hodge, M.S. Obin, X. Gong, F. Shang, T.R. Nowell Jr., J. Gong, H. Abasi, J. Blumberg, A. Taylor, Regulation of ubiquitin-conjugating enzymes by glutathione following oxidative stress, J. Biol. Chem. 272 (1997) 28218-28226.

[40] M. Obin, F. Shang, X. Gong, G. Handelman, J. Blumberg, A Taylor, Redox regulation of ubiquitin-conjugating enzymes: mechanistic insights using the thiol-specific oxidant diamide, FASEB J. 12 (1998) 561-569.

[41] B.S. Berlett, E.R. Stadtman, Protein oxidation in aging, disease, and oxidative stress, J. Biol. Chem. 272 (1997) 20313-20316. 